BULETINUL INSTITUTULUI POLITEHNIC DIN IAŞI

\section{sciendo}

DOI: 10.2478/BIPMF-2021-0006
(BULLETIN OF THE POLYTECHNIC INSTITUTE FROM IAȘI)

Published by "Gheorghe Asachi" Technical University of Iasi

Volume 67(71), No. 2, 2021

Section Mathematics Theoretical Mechanics. Physics

\title{
THE RELAXATION EFFECTS IN THE PREISACH - NÉEL MODEL OF PATTERNED MEDIA
}

\author{
ANA CAZACU ${ }^{1}$, CRISTIAN ROTĂRESCU ${ }^{2}$ and ILIE BODALE ${ }^{1, *}$ \\ 1"Ion Ionescu de la Brad" University of Agricultural Sciences and Veterinary Medicine, \\ Department of Exact Sciences, Faculty of Horticulture, Iaşi, Romania \\ ${ }^{2}$ National Institute of Research and Development for Technical Physics, Iaşi, Romania
}

Received: March 5, 2021

Accepted for publication: April 16, 2021

Abstract. In this paper, we present the calculation of thermal magnetic viscosity based on numerical simulations of relaxation isotherms curves for a Stoner-Wohlfarth ensemble. The Stoner-Wohlfarth particles is described by two equilibrium states and thermal activation is done by overcoming the energy barrier. For simulations we have used a new Preisach type model for Patterned Media, which takes into account the effects of time and temperature. The magnetization of the system is treated using the Preisach Model for Patterned Media with bimodal interactions field distributions. We have simulated relaxation curves starting from different points on the negative region of the descending branch of the major hysteresis loop and from the obtained data we evaluated the thermal fluctuation field. The results obtained for the linear energy barrier were compared with the non-linear energy barrier.

Keywords: Preisach Model for Patterned Media; Preisach - Néel model; magnetization relaxation; thermal magnetic viscosity; linear energy barrier; nonlinear energy barrier.

*Corresponding author; e-mail: ilie.bodale@uaiasi.ro

(C) 2021 Cazacu A. et al. This is an Open access article licensed under the Creative Commons Attribution-Non Commercial - No Dericatives 4.0 International License (CC BY-NV-ND 4.0) 


\section{Introduction}

In the last years, a considerable effort was dedicated to the profound understanding of relaxation effects in nanostructured materials due to their technological applications.

The Classical Preisach Model (CPM) (Preisach, 1935) describes a static magnetization process in which the effect of relaxation is neglected. To explain the dependence of the magnetization on the value of the applied field, vectorial magnetic phenomena, dynamic interaction, time and temperature effects, various Preisach-type models have been developed.

The effect of time and temperature in the magnetization processes was first described by Néel (Néel, 1949) and the model which he proposed can give good results if interactions between the neighboring entities are neglected.

For explaining the magnetization process of interacting particles systems, the Preisach-Néel model (PNM) was developed (Roshko and Viddal, 2004).

For systems with strong interactions distribution, a new Preisach-type model was developed, i.e. the Preisach Model for Patterned Media $\left(\mathrm{PM}^{2}\right)$ (Stancu et al., 2005). The $\mathrm{PM}^{2}$ combines ideas from the Generalized Preisach Model (Mayergoyz, 2003) and Moving Preisach Model (Stancu et al., 2001) using a two peaks interaction field distribution.

The evaluation of the energy in the $\mathrm{PM}^{2}$ for a particle is done in a similar manner like in the Stoner - Wohlfarth (SW) (Stoner et al., 1948), where the stable equilibrium position of the magnetization vector of each particle is determined by minimizing the expression of the energy imposing the equilibrium conditions.

The height of the energy barrier (3) is given by the difference between the maximum energy corresponding to the unstable equilibrium position $E\left(\theta_{m}\right)$ (1) and the energy corresponding to the stable equilibrium position of the polarization vector $E\left(\theta_{ \pm}\right)(2)$ :

$$
\begin{gathered}
E_{M}=\frac{V P_{S} H_{k}}{2}\left(1+\frac{H^{2}}{H_{k}^{2}}\right)=V P_{S} H_{k}+\Delta E_{S W} \\
E_{ \pm}= \pm V P_{S} H \\
\Delta E_{ \pm}=V P_{S}\left(H_{k} \pm H\right)^{2}
\end{gathered}
$$

Equation 3 describes the non-linear energy barrier of Stoner - Wohlfarth system.

If the SW energy $\left(\Delta E_{S W}=0\right)$ is neglected (Mitchler et al., 1997), then the energy barrier becomes linear (Fig. 1b): 


$$
\Delta E_{ \pm}=V P_{s}\left(H_{k} \pm H\right)
$$

The energy barrier can be overcome by a combination of an external magnetic field $\left(H_{a}\right)$ and an effective thermal viscosity field (Néel, 1949):

$$
H_{T}=H_{f} \ln \frac{t}{\tau_{0}}
$$

where $H_{f}=\frac{k T}{V P_{s}}$ is the thermal fluctuation field, $t$ is the experimental time and the $\tau_{0}$ is the critical time for switching the magnetic moments of the domains which is typically about $10^{-9} \div 10^{-12} \mathrm{~s}$.

\section{The Model}

The magnetic moment of particle in $\mathrm{PM}^{2}$ is evaluated like in CPM, where each particle is associated with a point in the Preisach plane, the coordinates being the switching fields $H_{\alpha}, H_{\beta}$ (Fig. $1 a$ ).

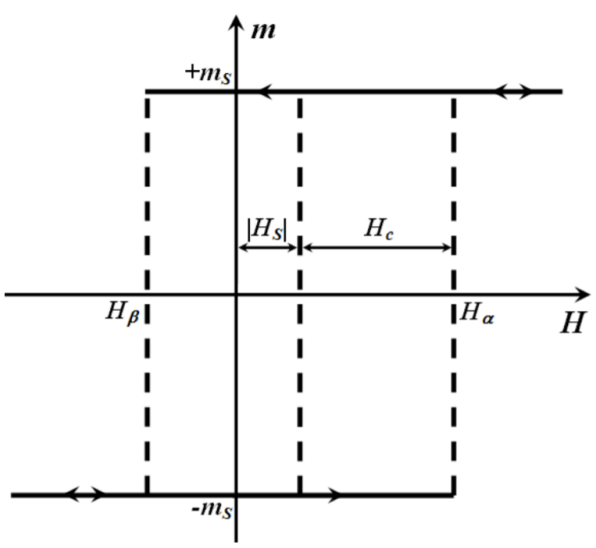

(a)

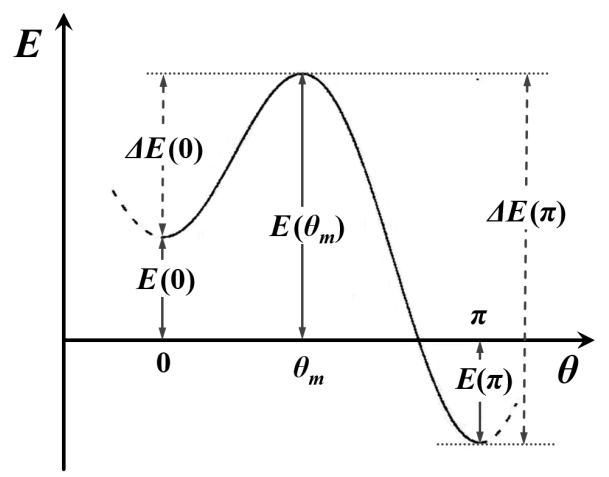


(b)

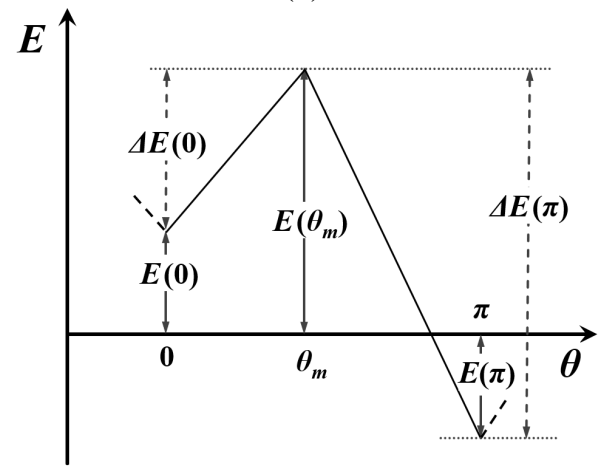

(c)

Fig. 1 - The rectangular hysteresis loop for a single domain called hysteron $(a)$, the associated Stoner - Wohlfarth double well potential in non-linear barrier energy $(b)$ and linear barrier energy $(c)$.

In the PNM, each particle/domain can exceed the energy barrier due to the effects of time and temperature, even in a zero applied field (Fig. $1 b$ and $1 c$ ).

In the Preisach Model for Patterned Media type model the magnetic moment includes bimodal interactions field distributions with the amplitude dependent on the magnetic state of the system (Cimpoesu et al., 2006).

In the CPM (Stancu et al., 2001) the magnetization is described by the product of two statistically independent distributions (6) given by the coercive (6') and interaction field distribution, while in the $\mathrm{PM}^{2}$ (Preisach, 1935) the independent distribution has two peaks (6").

The Preisach distributions in $\mathrm{PM}^{2}$ are written using $\left(h_{c}, h_{i}\right)$ reduced coordinate system (Fig. 2), which is rotated $45^{\circ}$ with respect to the $\left(H_{\alpha}, H_{\beta}\right)$ coordinates:

$$
\begin{gathered}
p\left(H_{\alpha}, \mathrm{H}_{\beta}\right)=\mathrm{p}_{i}\left(h_{i}\right) \cdot p_{c}\left(h_{c}\right) \\
P_{c}\left(h_{c}\right)=\frac{1}{\sqrt{2 \pi} h_{c \sigma}} \exp \left[-\frac{\left(h_{c}-h_{c 0}\right)^{2}}{2 h_{c \sigma}^{2}}\right] \\
p_{i}\left(H_{\alpha}, H_{\beta}\right)=\frac{1}{2 \sqrt{2 \pi} h_{i \sigma}}\left\{\exp \left[-\frac{\left(h_{i}-h_{i 0}\right)^{2}}{2 h_{i \sigma}^{2}}\right]+\exp \left[-\frac{\left(h_{i}+h_{i 0}\right)^{2}}{2 h_{i \sigma}^{2}}\right]\right\}+ \\
\frac{m}{2 \sqrt{2 \pi} h_{i \sigma}}\left\{\exp \left[-\frac{\left(h_{i}-h_{i 0}\right)^{2}}{2 h_{i \sigma}^{2}}\right]-\exp \left[-\frac{\left(h_{i}+h_{i 0}\right)^{2}}{2 h_{i \sigma}^{2}}\right]\right\}=p_{i, 0}\left(h_{i}\right)+m \cdot p_{i, m}\left(h_{i}\right)
\end{gathered}
$$

where $h_{c \sigma}$ are the standard deviations for coercive field, $h_{i \sigma}$ are the standard deviations for dynamic interaction effect, $h_{c o}$ is the most probable coercive field 
for dynamic interaction effect, $h_{i 0}$ the most probable interaction field and $m$ is the magnetization moment.

The effect of dynamic interaction (Borcia et al., 2002) leads to an increasing of the energy barrier height and $h_{c 0}$ is a function of saturation superparamagnetic moment of the sample $m_{\text {spm }}$.

$$
h_{c 0}=h_{c 0_{\text {static }}}+m_{\mathrm{spm}} \cdot \Delta h_{c 0}
$$

where $h_{c 0}$ static is the most probable value for the coercive distribution when the dynamic interaction effect is neglected and $\Delta h_{c 0}$ is a positive constant proportional with the strength of dynamic interactions.

The interaction field distribution is decreasing accordingly to the equation below:

$$
h_{i \sigma}=h_{i \sigma_{\text {static }}}-m_{\mathrm{spm}} \cdot \Delta h_{i \sigma}
$$

where $h_{i \sigma_{\text {static }}}$ is the standard deviation for the static interaction and $\Delta h_{i \sigma}$ is a positive constant that for the maximum value of the $\left(m_{\mathrm{spm}} \cdot h_{i \sigma}\right)$ is very close to zero.

The memory region of Preisach plan is divided into four regions (Fig. 2). The particles from three of these regions are superparamagnetic (1,2 and 3) and the particles from region 4 remain blocked in their previous state. For example, in Fig. 2, all domains from region 4 are blocked in the "+" state and they switch if they are swept by the $b_{\text {linear }}$ energy barrier line or $b_{\text {nonlinear }}$ curve, respectively. Instead, the region 1 remains superparamagnetic.

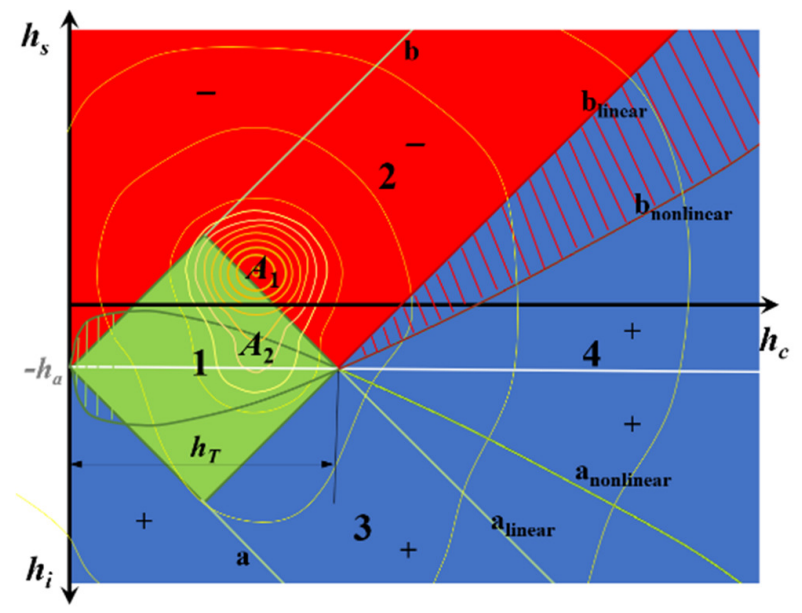

Fig. 2 - The 2D diagram of Preisach plane in $\left(h_{c}, h_{i}\right)$ coordinate system, rotated $45^{\circ}$ with respect to the $\left(H_{0}, H_{\beta}\right)$ axis in a negative applied field $\left(-h_{a}\right)$. The particles from $1^{\text {st }}$, $2^{\text {nd }}$ and $3^{\text {rd }}$ regions are superparamagnetic and the particles from the $4^{\text {th }}$ region are 
blocked in the previously state. The two peaks of interaction field distribution, $\mathrm{A}_{1}$ and $\mathrm{A}_{2}$, are represented in the demagnetization state.

We extended the $\mathrm{PM}^{2}$ taking into account the effects of time and temperature (Néel, 1949), the Preisach - Néel Model for Patterned Media (PM²Néel Model). This model solves the effects of time and temperature, without neglecting the strong interaction distribution.

The most important effect of time on magnetization phenomena is magnetic viscosity (also, named magnetic aftereffect).

In this approach for evaluating the relaxation phenomena we have studied the relaxation curves starting from points on the negative region of the descending branch of the major hysteresis loop and from these data we have calculated the thermal fluctuation using the procedure presented by Della Torre in 2002 and extended by Roshko and Viddal in 2005. The relaxation curves were simulated for different negative applied fields. We have also calculated the thermal fluctuation field from numerical simulations of viscosity isotherms based on the double well potential and the simulations obtained using a non-linear energy barrier were compared with those obtained using a linear energy barrier.

\section{Numerical Simulations}

To determine the thermal viscosity, we have generated a numerical simulation using the Preisach formalism with the magnetic moment dependent on the magnetic state of the system. The magnetic relaxations in the PM²-Néel Model presented above were simulated for a Stoner - Wohlfarth system characterized by bimodal interactions field distributions.

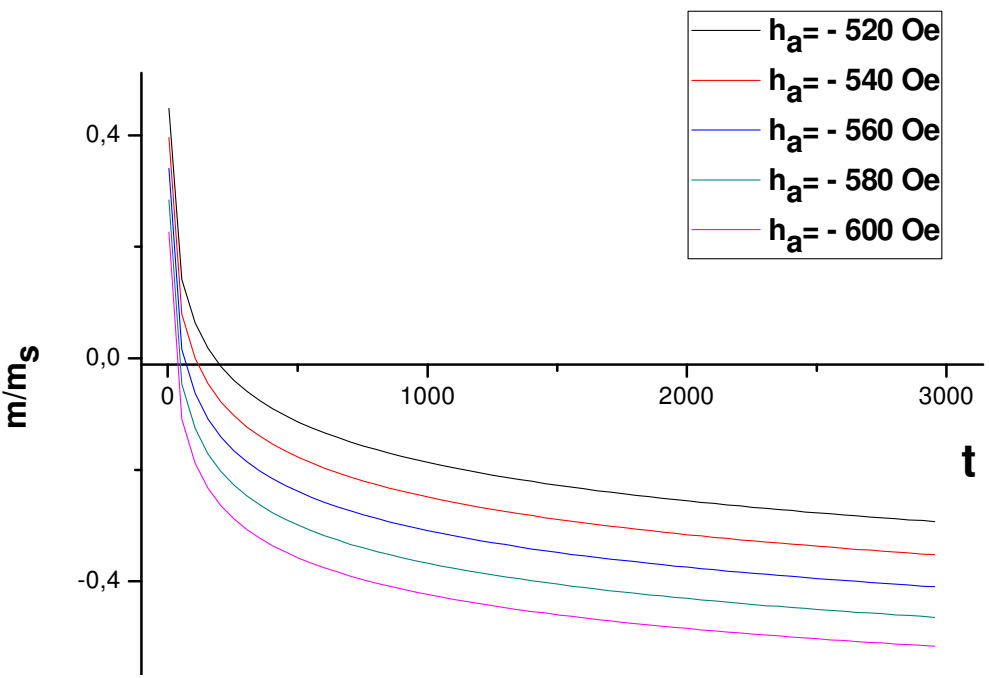

Fig. 3 - The magnetic relaxation isotherms curves simulated for different applied fields 
(520 Oe, $540 \mathrm{Oe}, 560 \mathrm{Oe}, 580 \mathrm{Oe}$ and $600 \mathrm{Oe}$ ) at $T=35 \mathrm{~K}$ for a non-linear energy barrier system.

The parameters used were: $h_{c 0_{\text {static }}}=1000$ Oe, $h_{c \sigma}=200$ Oe, $h_{i \sigma_{\text {static }}}=$ 200 Oe, $h_{i 0}=200$ Oe and $\Delta h_{c \sigma}=300$ Oe for both cases, linear and non-linear energy barrier. We simulated the viscosity isotherms for a fixed time range $(5 \mathrm{~s}$ $\div 3 \cdot 10^{3} \mathrm{~s}$ ). Magnetic relaxation isotherms curves were simulated at $T=35 \mathrm{~K}$ for a series of negative applied fields $\left(-h_{a}\right): 520$ Oe, 540 Oe, 560 Oe, 580 Oe and 600 Oe and are presented in Fig. 3.

For each magnetic relaxation isotherms curve, the critical time of $m(t)=0$ condition was calculated (Roshko and Viddal, 2005). The logarithmical critical time of relaxation isotherms was plotted as a function on the negative applied field.

The viscosity isotherms were analyzed as a function of temperature over the $10 \mathrm{~K} \leq T \leq 175 \mathrm{~K}$ interval and universal curve was obtained for both cases, linear and non-linear energy barrier (Fig. 4).

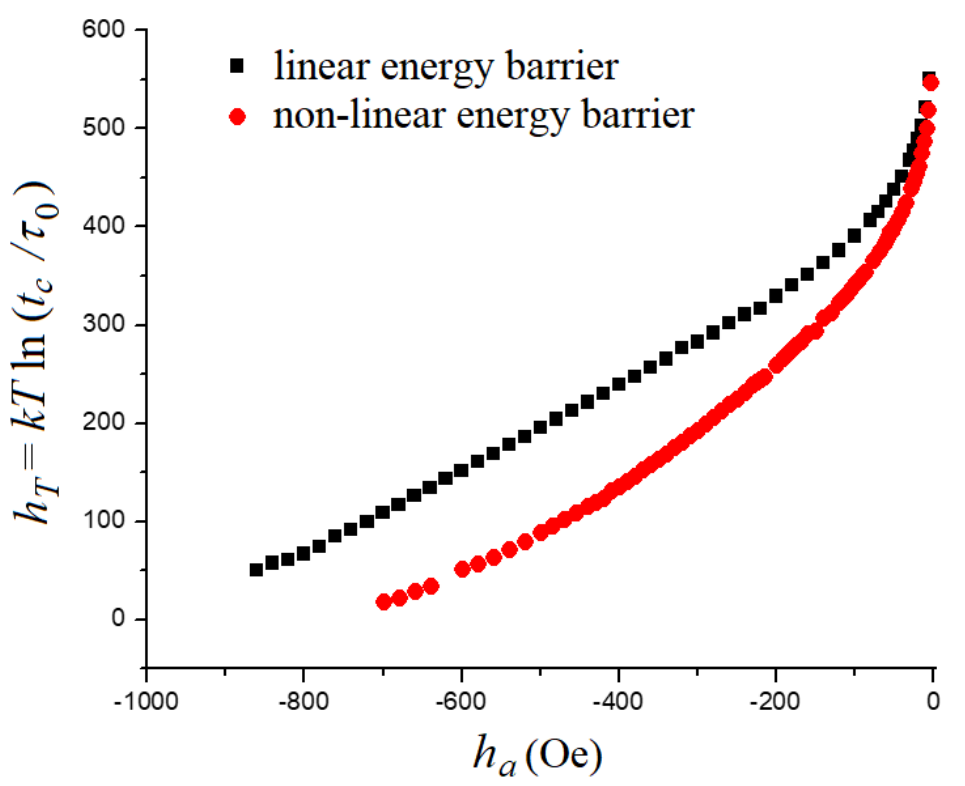

Fig. 4 - The universal curves of $h_{T}$ as a function of the applied field $\left(-h_{a}\right)$ from numerical simulations of viscosity isotherms. 
The thermal viscosity field $\left(h_{T}\right)$ as a function of temperature $(T)$ was simulated for both types of energy barriers. The simulations showed that the maximum values are at $125 \mathrm{~K}$, regardless of the type of barriers chosen (Fig. 5).

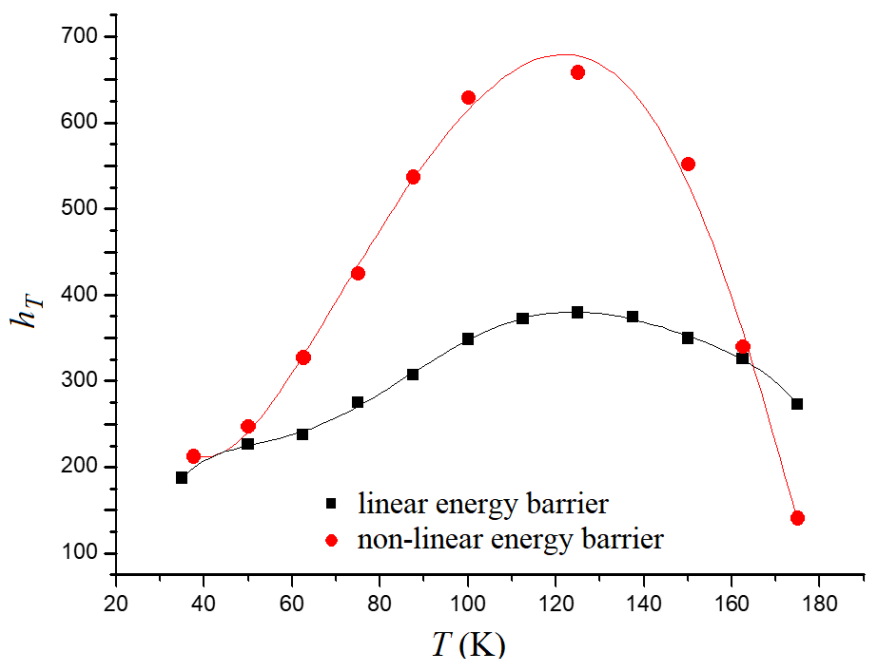

Fig. 5 - The thermal viscosity field plotted as a function of temperature for simulation of the relaxation curves in time range $\left(5 \div 3 \cdot 10^{3} \mathrm{~s}\right)$.

\section{Conclusions}

A new Preisach Model for Patterned Media type model that considers the effects of time and temperature was developed to evaluate the thermal magnetic viscosity. The advantage of this model is that it considers both static and dynamic interactions from patterned media. The simulation shows that the viscosity isotherms field depends non-linearly as a function of the applied field and temperature.

In the two cases considered, particles switch faster in the case of the linear barrier, which shows that the value of the thermal magnetic viscosity is lower.

Acknowledgements. Work supported by the Executive Unit for Financing Higher Education, Research, Development and Innovation (UEFISCDI) under the project PN-III-P4-ID-PCE-2020-1856 (contract no. PCE 1/2021).

\section{REFERENCES}


Borcia I., Spanu L., Stancu A., A Preisach-Neel Model with Thermally Variable Variance, IEEE Transactions on Magnetics, 38, 5, 2415-2417 (2002).

Cimpoesu D., Spinu L., Stancu A., Relaxation Effects in Interacting Nanostructured Particulate Systems, Journal of Applied Physics, 99, 08G105 (2006).

Della Torre E., Bennett L.H., Fry R.A., Ducal O.A., Preisach-Arrhenius Model for Thermal Aftereffect, IEEE Transactions on Magnetics, 38, 5, 3409-3416 (2002).

Mayergoyz I.D., Mathematical Models of Hysteresis and their Applications, $1^{\text {st }}$ Ed., Amsterdam, Boston: Elsevier, 2003.

Mitchler P.D., Roshko R.M., Dahlberg E.D., A Preisach Model with a Temperature and Time-Dependent Remanence Maximum, Journal of Applied Physics, 81, 52215226 (1997).

Néel L., Théorie du traînage magnétique des ferromagnétiques en grains fins avec application aux terres cuites, Annales de Géophysique, 5, 99-136 (1949).

Preisach F., Über die magnetische Nachwirkung, Zeitschrift für Physik, 94, 277-302 (1935).

Roshko R.M., Viddal C.A., Interpreting Remanence Isotherms: A Preisach-Based Study, European Physics Journals B, 40, 145-151 (2004).

Roshko R.M., Viddal C.A., Non-Arrhenius Relaxation Effects in Collections of TwoLevel Subsystems, Physical Review B, 72, 184422 (2005).

Stancu A., Stoleriu L., Cerchez M., Micromagnetic Evaluation of Statistical and MeanField Interactions in Particulate Ferromagnetic Media, Journal of Magnetism and Magnetic Materials, 225, 411-417 (2001).

Stancu A., Stoleriu L., Postolache P., Tanasa R., New Preisach Model for Structured Particulate Ferromagnetic Media, Journal of Magnetism and Magnetic Materials, 290, 490-493 (2005).

Stoner E.C., Wohlfarth E.P., A Mechanism of Magnetic Hysteresis in Heterogeneous Alloys, Philosophical Transactions of the Royal Society of London, Series A, Mathematical and Physical Sciences, 240, 599-642, 1948.

\section{EFECTELE DE RELAXARE ÎN MODELUL PREISACH - NÉEL DIN MEDIILE NANOPARTICULATE}

(Rezumat)

În această lucrare este prezentat calculul vâscozității magnetice termice pe baza simulărilor numerice ale curbelor izotermelor de relaxare pentru un ansamblu Stoner Wohlfarth. Particulele Stoner - Wohlfarth sunt descrise prin două stări de echilibru care pot comuta prin activare termică. Pentru simulări s-a folosit un nou model de tip Preisach pentru medii particulate (ordonate) care iau în considerare efectele timpului și temperaturii. Magnetizarea sistemului este calculată utilizând modelul Preisach pentru medii ordonate cu distribuții bimodale de interacțiuni de câmp. Au fost simulate curbele de relaxare magnetică din diferite puncte de pe regiunea negativă a ramurii descendente a ciclului major de histerezis și din datele obținute s-a evaluat câmpul de fluctuație 
termică. Rezultatele obținute pentru bariera de energie liniară au fost comparate cu bariera de energie neliniară. 